\title{
Papillary-Reticular Dermal Interface
}

National Cancer Institute

\section{Source}

National Cancer Institute. Papillary-Reticular Dermal Interface. NCI Thesaurus. Code C94493.

The skin layer that separates the papillary dermis from the reticular dermis. 